\title{
LETTER
}

\section{Soluble CD40 ligand is not solely related to the presence and severity of sepsis}

\author{
Michelle S Chew* and Henrik Thorlacius \\ See related research by Lorente et al., http://ccforum.com/content/15/2/R97
}

We read with interest the recently published paper by Lorente and colleagues reporting that levels of soluble CD40 ligand (CD40L) are increased in septic patients compared with healthy controls and that increased circulating CD40L levels may be an independent predictor of mortality in patients with sepsis [1]. The relationship between platelets and soluble CD40L seen in this study is consistent with previous data showing that soluble CD40L is mainly released from activated platelets and mediates neutrophil-induced lung injury in sepsis [2].

We believe that the functional role of soluble CD40L is complex, however, and not solely related to the presence of sepsis or its severity. This is indicated in the study by Lorente and colleagues, in which no associations were found between soluble levels of CD40L and Acute Physio- logy and Chronic Health Evaluation scores, Sequential Organ Failure Assessment scores, and TNF $\alpha$ and IL-10 levels [1], which is in agreement with previous findings $[3,4]$. Further, although the study was conducted in patients with sepsis, we suggest that soluble CD40L is a common denominator for patients with shock, rather than with sepsis per se. Thus, in a study of critically ill patients admitted to the intensive care unit with shock due to different aetiologies, we found no differences in the levels of soluble CD40L between septic and nonseptic shock patients [4]. The relevance of soluble CD40L as a potential therapeutic target for sepsis therefore remains to be explored.

We suggest that targeting CD40L in order to ameliorate pathological inflammatory responses is not limited to septic patients but also includes nonseptic shock patients.

\section{Authors' response}

Leonardo Lorente, María del Mar Martín, Nerea Varo and José Antonio Páramo

We read with interest the letter by Chew and Thorlacius discussing our recent manuscript showing that circulating levels of soluble CD40L were associated with mortality in sepsis [1].

Chew and Thorlacius stated that the functional role of soluble CD40L is complex and not solely related to the presence of sepsis; they suggested that soluble CD40L is a common denominator for patients with shock, rather than with sepsis per se. Indeed, in a recent study these authors found higher soluble CD40L levels in patients with nonseptic shock and septic shock than in healthy controls, but the levels were no different between patients with nonseptic shock and patients with septic shock [4].

We have reanalysed the data from our study, and we found higher serum soluble CD40L levels in patients with

*Correspondence: Michelle.Chew@med.lu.se

Department of Intensive Care Medicine, Skåne University Hospital Malmö, S-20502 Malmö, Sweden severe sepsis without septic shock (3.92 (2.60 to 5.60) $\mathrm{ng} / \mathrm{ml} ; P=0.01)$ or with septic shock (4.54 (2.78 to 6.70$)$ $\mathrm{ng} / \mathrm{ml} ; P=0.001)$ than in healthy controls (3.29 (2.10 to 4.19) $\mathrm{ng} / \mathrm{ml}$ ). We do not, however, have data about soluble CD40L in septic shock and nonseptic shock. We can conclude that soluble CD40L could play a role in the inflammatory response, whether or not shock is present.

\section{Abbreviations}

CD40L, CD40 ligand; IL, interleukin; TNF, tumour necrosis factor.

\section{Competing interests}

The authors declare that they have no competing interests.

\section{Published: 3 August 2011}

\section{References}

1. Lorente L, Martin MM, Varo N, Borreguero-León JM, Solé-Violán J, Blanquer J, Labarta L, Diaz C, Jiménez A, Pastor E, Belmonte F, Orbe J, Rodriguez JA, Gómez-Melini E, Ferrer-Aguero JM, Ferreres J, Lliminana MC, Páramo JA: Association between serum soluble CD40 ligand levels and mortality in patients with severe sepsis. Crit Care 2011, 15:R97.

2. Rahman M, Zhang S, Chew M, Ersson A, Jeppson B, Thorlacius H: Platelet derived CD40L (CD154) mediates neutrophil upregulation of Mac-1 and recruitment in septic lung injury. Ann Surg 2009, 250:783-790. 
3. Nolan A, Weiden M, Kelly A, Hoshino Y, Hoshino S, Mehta N, Gold JA: CD40 and $C D 80 / 86$ act synergistically to regulate inflammation and mortality in polymicrobial sepsis. Am J Resp Crit Care Med 2008, 177:301-308.

4. Chew M, Rahman M, Ihrman L, Ersson A, Zhang S, Thorlacius H: Soluble CD40L (sCD40L) is increased in patients with shock. Inflamm Res 2010 59:979-982 doi:10.1186/cc10316

Cite this article as: Chew MS, Thorlacius H: Soluble CD40 ligand is not solely related to the presence and severity of sepsis. Critical Care 2011, 15:438. 